\title{
2004s-41 \\ On the Use of Hierarchies to Complete Contracts when Players Have Limited Abilities
}

\author{
M. Martin Boyer
}

\begin{tabular}{c}
\hline Série Scientifique \\
Scientific Series
\end{tabular}

Montréal

Août 2004

(C) 2004 M. Martin Boyer. Tous droits réservés. All rights reserved. Reproduction partielle permise avec citation du document source, incluant la notice $\mathbb{C}$.

Short sections may be quoted without explicit permission, iffull credit, including (C) notice, is given to the source.
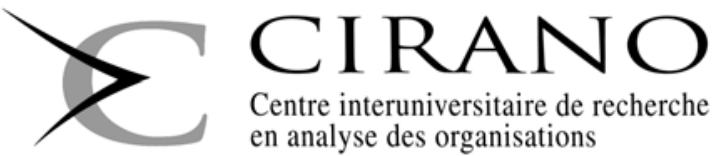

Centre interuniversitaire de recherche en analyse des organisations 


\section{CIRANO}

Le CIRANO est un organisme sans but lucratif constitué en vertu de la Loi des compagnies du Québec. Le financement de son infrastructure et de ses activités de recherche provient des cotisations de ses organisations-membres, d'une subvention d'infrastructure du Ministère du Développement économique et régional et de la Recherche, de même que des subventions et mandats obtenus par ses équipes de recherche.

CIRANO is a private non-profit organization incorporated under the Québec Companies Act. Its infrastructure and research activities are funded through fees paid by member organizations, an infrastructure grant from the Ministère du Développement économique et régional et de la Recherche, and grants and research mandates obtained by its research teams.

PARTENAIRE MAJEUR

Les organisations-partenaires / The Partner Organizations

. Ministère du Développement économique et régional et de la Recherche [MDERR]

PARTENAIRES

. Alcan inc.

. Axa Canada

. Banque du Canada

. Banque Laurentienne du Canada

. Banque Nationale du Canada

. Banque Royale du Canada

. Bell Canada

. BMO Groupe Financier

. Bombardier

. Bourse de Montréal

. Caisse de dépôt et placement du Québec

. Développement des ressources humaines Canada [DRHC]

. Fédération des caisses Desjardins du Québec

. GazMétro

. Hydro-Québec

. Industrie Canada

. Ministère des Finances du Québec

. Pratt \& Whitney Canada Inc.

. Raymond Chabot Grant Thornton

. Ville de Montréal

. École Polytechnique de Montréal

. HEC Montréal

. Université Concordia

. Université de Montréal

. Université du Québec à Montréal

. Université Laval

. Université McGill

. Université de Sherbrooke

Associe A :

. Institut de Finance Mathématique de Montréal (IFM²)

. Laboratoires universitaires Bell Canada

. Réseau de calcul et de modélisation mathématique $\left[\mathrm{RCM}^{2}\right]$

. Réseau de centres d'excellence MITACS (Les mathématiques des technologies de l'information et des systèmes complexes)

Les cahiers de la série scientifique $(\mathrm{CS})$ visent à rendre accessibles des résultats de recherche effectuée au CIRANO afin de susciter échanges et commentaires. Ces cahiers sont écrits dans le style des publications scientifiques. Les idées et les opinions émises sont sous l'unique responsabilité des auteurs et ne représentent pas nécessairement les positions du CIRANO ou de ses partenaires.

This paper presents research carried out at CIRANO and aims at encouraging discussion and comment. The observations and viewpoints expressed are the sole responsibility of the authors. They do not necessarily represent positions of CIRANO or its partners. 


\title{
On the Use of Hierarchies to Complete Contracts when Players Have Limited Abilities
}

\author{
M. Martin Boyer ${ }^{*}$
}

\begin{abstract}
Résumé / Abstract
Dans cet article je m'intéresse à la raison pour laquelle les organisations publiques comme privées ont recours à une hiérarchie informationnelle. Je propose un modèle théorique qui explique l'existence des hiérarchies comme étant un outil nécessaire pour aider les agents à récolter le plus d'information possible étant donné leurs capacités limitées. Ainsi, à cause de cette limite intellectuelle et/ou computationnelle des agents économiques au sein des organisations, le contrat complet est trop complexe pour être mis en oeuvre dans les organisations à moins d'utiliser une structure pyramidale pour gérer l'information. En fait, les hiérarchies permettent de récolter plus d'informations à moindre coût. Les contributions de l'article sont les suivantes: 1) il suggère une raison à l'existence des hiérarchies; 2) il développe une mesure de la quantité d'information qui doit être gérée au sein d'une organisation; 3) il mesure de manière endogène le nombre optimal de niveaux au sein de la hiérarchie organisationnelle étant donné les capacités limitées des agents; 4) il rationalise le fait d'avoir les individus les plus talentueux au haut de la pyramide; 5) il donne une explication au fait d'avoir un seul président dans l'organisation; et 6) il explique comment le nombre de niveaux et le nombre de gestionnaires varient lorsque l'entreprise grandit ou lorsque les tâches des agents changent.
\end{abstract}

Mots clés : hiérarchies, théorie des contrats, complexité, information corrélée.

Why do larger corporations have more layers in their hierarchy? My contention in this paper is that hierarchies arise because economic agents have limited ability to anticipate and ascertain every possible contingency they are faced with. As a result, the complete contract may become too complex (or too costly) to devise and manage directly. My contention in this paper is that hierarchies may help a limited-ability principal (the organization's president) collect all pertinent information about the productive elements in the organization so that the complete is again possible. The contributions of the paper are six-fold: 1) it suggests a reason why hierarchies exist; 2) it develops a measure of the quantity of information that needs to be processed at each level of the organization; 3 ) it measures endogenously the optimal number of layers in a hierarchy given the players' ability to process information; 4) it provides a rationale for having the most talented individuals at the top of the hierarchy; 5) it offers an explanation for the existence of an unique president in an organization; and 6) it explains how the number of layers and of managers may vary over time as the company grows and/or the players' ability changes.

Keywords: hierarchies, contract theory, complexity, correlated information.

Codes JEL : L22, D83

\footnotetext{
*Professeur agrégé (associate professor), Finance HEC Montréal, Université de Montréal, 3000, Côte-SteCatherine. Montréal, QC H3T 2A7; Fellow, CIRANO, 2020 University ave. Montréal, QC H3A 2A7.
} 


\section{Introduction}

\subsection{Motivation}

Almost every organization in the economy, whether public or private, closely-held or widely-held, for-profit or not-for-profit, has an internal structure which may be called hierarchical. All organizations have a residual claimant ${ }^{1}$ in the sense of Alchian and Demsetz (1972). Typically, the residual claimant is the agent who has the greatest incentive to monitor. In their theory of the firm, Jensen and Meckling (1979) argue that as soon as one departs from the owner-manager paradigm, agency costs are encountered so that inefficiencies arise. These agency costs are typically associated with having agents reveal their information to the principal, or with ways to assure that one firm stakeholder does not extract undue rents from the other stakeholders. Since one of the most prevalent agency costs is linked to the human capital / labor production within the firm, most studies in economics and finance have concentrated on two distinct levels of pyramid-like organizations: The top and the bottom.

Research that focuses on the top part of an organization in a for-profit organization is known as the CEO compensation literature. Research focusing on the bottom part of the organization may be loosely agglutinated under the general terms wages and workers. In both cases the academic literature is quite extensive as it is evident in the entire set of Handbooks of Labor Economics. Other firm stakeholders have also found they day in the spotlight: Creditors, government, stockholders, blockholders and financial institutions. Basically all firm stakeholders, from capitalists to productive laborers, from managers to creditors and from the government to different types of capitalists have been studied in major academic journals in both economics and finance.

One group of stakeholders that have largely been ignored in the economic literature are those who, within a firm, sit between top management and the productive laborers. With few exceptions such as Lindbeck and Snower (2000), middle management has not been the focus of much attention by economists. In contrast, the management literature has devoted more attention to the study of the strengths and weaknesses of middle management in organizations. This is particularly true in the industrial relation, organizational behavior and human resource literature. ${ }^{2}$

One may then wonder why economists have such little interest in the study of middle management? This apparent lack of interest is somewhat surprising given that middle managers represent an important sub-group of the labor force. As a case in point, Radner (1992) reports that, in the United States, managers at all levels of every organization represent roughly one-third of the labor

\footnotetext{
${ }^{1}$ See, however, Hollander (1903) for a very early critique of the residual claimant theory in economics.

${ }^{2}$ See, for example, Cannings (1988) in labor relations, Floyd and Wooldridge (1992) and Guth and Macmillan (1986) in strategy, and Pinsonneault and Kraemer (1997) and White et al. (1999) in information systems.
} 
force. The proportion of managers in the labor force has steadily increased in the last eighty years as organizations have increased in size.

One possible explanation for the general lack of interest in the study of middle managers is that they are not "real workers" (see Radner, 1993). This may be associated with the fact that most managerial duties in an organization involve the information processing rather than decision making (see Radner, 1992). As a result, the managers' major purpose in any organization is to relay information back and forth between the top and the bottom layers of the organizational hierarchy. This then begs the question of how valuable is information processing for an organization? Also, what type of information and how much information needs to be processed? The economic literature appears to offer few answers to the value, the type and the sheer volume of information that flows within a firm. The goal of this paper is to offer an answer to these questions based on an economic approach to organizational design.

To that end, I present a model of information asymmetry in which productive agents (the "workers") possess information that needs to reach the principal (the "president"). Any agents' compensation is linked to the type of information that reaches the upper echelon of the organization. Because I shall assume that one agent's information is possibly correlated with the information of other agents, a principal (or the managers or the agents' supervisors) may use one agent's report to condition the compensation of the others. If it is feasible to write very long contracts that can take into account any and all possible contingencies (in other words, if the principal is able to write a complete contract), then by the revelation principle (see Myerson, 1982) a centralized organization (1 principal, $\mathrm{N}$ agents) can do no worse than a decentralized organization.

Very long (and complete) contracts may be too costly to implement, however, as shown by Williamson (1975). Similarly, Melumad et al. (1997) assert that when the agents' tasks become more complicated, complete contracts become longer and more costly to write.

When the supervision of the workers becomes more and more difficult, the president of the organization may need to hire managers to screen and oversee the information transmitted by the agents; this is the foundation for the creation of an informational hierarchy within the organization (see Bolton and Dewatripont, 1994). On the downside, when the principal creates a hierarchy, he delegates some power to managers; a process that is indubitably costly, if only in terms of giving a wage to the manager. On the up-side, the use of a hierarchy increases the flow of information within the organization. As a result, a firm's president whose limited ability prevents him from keeping track of all possible contract contingencies will need to rely on managers as a mean to complete the contact between him and the productive workers.

The complexity of middle manager compensation may be due to the fact that it is very hard to 
define their duties from one firm to another. Radner (1992) offers a list of nine tasks that managers are asked to do in organization, including 1- observing the environment and the result of past actions, 2-processing and communicating the information, and 3- monitoring the actions of other firm members. These are the three tasks that are asked of managers in my paper.

In essence, my paper provides a new insight into the reason why hierarchies exist based purely on the need to complete the contract that binds the company's president with the workers.

\subsection{Contribution and Results}

As I shall demonstrate, complete contract compensation schemes quickly become extremely complex when information is correlated across agents, when the number of agents bounded by the terms of the contract increases and when the number of possible types increases. Complete contracts may even perhaps be too complex to be implemented realistically so that firms resort to simple compensation schemes such as pay scales, loose monitoring policies and experience-based promotion, instead of spending resources in designing the complete contract. Although simple schemes may allow agents to extract rents from the principal, these rents may conceivably be smaller than the cost of writing the complete contract.

Rather than offering a justification for the use of simple compensation schemes, my results offer a rationale for the existence of hierarchies in an organization. When individuals have limited abilities to manage complex contracts (see Geanakoplos and Milgrom, 1991, Radner, 1992, Baniak and Cukrowski, 1999, Orbay, 2002), I find that hierarchies become a way to transmit information more efficiently. Through the use of a hierarchy, it becomes relatively less complex for managers in the upper echelon of the organization to gain access to the information of lower echelon agents. The number of echelons in the hierarchy then depends on the individuals' ability to manage the many different provisions of the complete contract.

My paper develops a complexity measure based on the number of parameters that need to be specified in a complete contract between a principal and the agents under the assumption that agents are risk averse, have limited liability and possess correlated information about their types. Given this complexity measure, I present how informational hierarchies come to be as the firm's president needs to aggregate all the information that the agents possess. The algorithm used allows me to observe what happens to an organization when the complexity of the productive agents' tasks increases, when the number of productive agents in the organization increases and when the technology at the disposal of the managers allows them to supervise more productive agents. As a result, I am able to explain why the shape of organizations differs from one industry to the next, how organizations evolve over time and why larger organizations have more managerial layers. 
The model I present does not address directly the question of the monetary cost of implementing a given hierarchy. I am instead concerned with the manner in which an organization can structure itself so that all the information is transmitted to the penultimate principal in the organization. To my knowledge, this is the first paper to suggest that hierarchies exist to complete contracts in a world where agents possess correlated private information and where managers have a limited ability in keeping track of all contract contingencies.

More specifically, the contributions of the paper are six-fold: 1- it suggests a reason why hierarchies exist; 2- it develops a measure of the quantity of information that needs to be processed at each level of the organization; 3 - it measures endogenously the optimal number of layers in a hierarchy given the players' ability to process information; 4 - it provides a rationale for having the most talented individuals at the top of the hierarchy; 5 - it offers an explanation for the existence of an unique president in an organization; and 6-it explains how the number of layers and of managers may vary over time as the company grows and/or the players' ability changes.

The paper is constructed as follows. In the next section I present how my paper fits in the literature on contract theory under asymmetric information, on contract complexity and on hierarchies. I present in Section 3 the algorithm used to measure how much information must be transmitted in the organization so that contracts become complete. In Section 4 I show how the use of hierarchies enable the principal to complete contracts. Section 5 presents predictions as to the shape of different organizations, the impact of better technology on the organizations, and the compensation of players within an organization and across organizations. Finally section 6 concludes with a discussion of the limitations of the model and further insights into the problem.

\section{Standing on the Shoulders of Giants}

\subsection{Contracts and Hierarchies}

Segal (1999) defines a contract to be complex if it is rational for players ex ante to ignore contingencies that may occur ex post. Another interpretation could be that complexity arises in a contract if it is too costly for players to keep track of all its possible contingencies. As a result an agent may disregard a certain number of contingencies. This has given rise to the incomplete contract literature.

The incomplete contract literature is extensive, and I do not want to get into it. ${ }^{3}$ My focus is not on contract incompleteness, but rather on the high cost of keeping track of all the possible contingencies of a contract. A recent paper by Rasmusen (2001) presents a model where contract

\footnotetext{
${ }^{3}$ See for example Hart and Moore (1988) and Maskin and Tirole (1999).
} 
incompleteness stems from the cost of reading (rather than writing) complete contracts. What I shall term contract complexity will merely be the number of variables that need to be specified in a complete contract. As such I deviate from the computational economic view of complexity (see Anderlini and Felli, 1994, 1999) and focus instead on developing a complexity measure as in Dye (1985). In short, contract complexity in my model stems from the "bounds on individuals' capabilities for information processing and decision making." (Radner, 1992, page 1384). As a result, my definition of contract complexity is in line with that of Melumad et al. (1997) who write

"Since each contingency has to be specified in advance as part of the formal contract, ...., contracts with more contingencies are more expensive to write and understand." 4

Following the transaction-cost literature, a contract will become too complex when a player does not have the intellectual capacity to cope with all the contingencies that must be included in the contract. In that respect, my approach to contract complexity is similar to Dye (1985), Geanakoplos and Milgrom (1990) Radner (1993), Melumad et al. (1997), Segal (1999) and Orbay (2002). ${ }^{5}$ My approach is also related to the one used by Radner and VanZandt (1992) and Bolton and Dewatripont (1994) although I shall use a static rather than dynamic approach to the information. I model the players' limited ability very naively: Their ability is limited by an upper bound on the number of contract parameters one can keep track of. ${ }^{6}$ As the number of contingencies rises above the maximum a player is capable of handling, it becomes necessary either to have more players in the organization, or to accept that the contract remains incomplete. When the choice is to hire more and more players, the creation of a hierarchy may become the only way to complete contracts within the organization.

The compensation of middle management has usually been viewed as a contracting problem within a hierarchy. As such Williamson (1967) concludes that the size of an organization, and more precisely the number of layers in the organization, is an important determinant of a firm's efficiency to transmit information within the organization. Information transmission efficiency becomes even more important in the hierarchy when the agents' actions are not completely observable. Following that line of thought, the sole purpose of the organizational hierarchy I present is to transmit information from the organization's lower echelons to its upper echelon, as in Bolton and Dewatripont

\footnotetext{
${ }^{4}$ Melumad et al. (1997), page 259.

${ }^{5} \mathrm{My}$ measure of complexity has some of the drawbacks exposed in Hart and Holmström (1987) and Anderlini and Felli (1999). For example my definition, and that of Dye (1985), of what is complex and what is not is arguably ad hoc since I define complexity as the number of variables (or the number of contingencies) that need to be determined to complete the contract. This does not cause too much problem when the contingencies are discreet as here, but may be troublesome when contingencies are distributed on a continuum. See also Melumad et al. (1997) for a counterpoint to the Hart and Holmström (1987) critique.

${ }^{6}$ Bolton and Dewatripont (1994) refer to this as "maximum flow return".
} 
(1994), Baniak and Cukrowski (1999) and Orbay (2002).

To illustrate, I will use the following example throughout the paper. Suppose an organization where lower echelon players (say the agents) have correlated information valuable to an unique upper echelon player (say the principal) so that the latter wants to design a contract that will extract as much information as possible from the former knowing that such information is correlated. This example applies to the case of a company president who must handout year-end bonuses to her managers or to the case of an university principal (no pun intended) who must decide which faculty member gets a pay raise this year. These bonuses are based on the manager's performance which is not known to the president. To gather that information, the president can choose to engage in a round of costly auditing or she can rely entirely on the managers' information or both.

\subsection{Information Extraction and Surplus}

Organizations routinely perform audits and use other forms of costly monitoring to gather information. Organizations defend the use of costly monitoring by arguing that it helps reduce adverse rent-seeking behavior by its members. Another argument is that revelation of information allows the upper echelon player to secure for himself the economic surplus created in the organization. In such a case the contract typically specifies a probability of audit in certain states of the world and a penalty if the audit reveals the agent's message to be false (see Townsend, 1979, Baron and Myerson, 1982, and Mookherjee and Png, 1989). Truth-telling is then induced through the use of regular credible audits. ${ }^{7}$ Unfortunately audits are costly so that it would be welfare-enhancing to extract all the information without having to resort to costly audits.

The approach pioneered by Crémer and McLean $(1985,1988)$ and McAfee and Reny (1992) CMMR hereafter - makes use of the agents' correlated information to show that truth-telling is possible without having to sacrifice either efficiency or surplus extraction (see also Aoyagi, 1998, and Brusco, 1998). What CMMR call full surplus extraction (FSE) is then possible even if the correlation between the agent's information is small, but not zero. FSE is achieved by making an agent's compensation independent of his announcement, but dependent on the other agents' announcement. As information is correlated, one agent's information should be related to the other agents' information.

Under certain conditions FSE is possible without the principal having to resort to costly audits. Why then is costly monitoring and performance evaluations so pervasive in the economy? The reason is that the compensating scheme devised in CMMR quickly becomes extremely risky for

\footnotetext{
${ }^{7}$ See Boyer (2003) and Khalil (1997) for the case where commitment is not possible and Krasa and Villamil (2000) for general issues dealing with renegotiation.
} 
the agents. More to the point, the contract in CMMR is designed so that, albeit with some small probability, an agent that has achieved a very good performance could be submitted to a hefty penalty (or the opposite) depending on the other agents' reports. Since CMMR rely heavily on the risk neutrality of agents and on the absence of limited liability, they are able to design a mechanism that includes arbitrarily high mean preserving spread transfers to which risk neutral agents are indifferent. Unfortunately, if agents are risk averse as in Robert (1991) or have limited liability as in Demougin and Garvie (1991), such penalties and bonuses turn out to be too large to induce participation. As a result, risk aversion and limited liability are possible explanations for the frequency of audits.

The efficiency of a compensation scheme depends ultimately on the agents' risk aversion and their information's degree of correlation. Auditing, which is another tool to induce truth-telling, should therefore be used more frequently when we have reached the limits of contract design; that is, when risk aversion is high and when information correlation is low. When information is independent from one agent to the next, auditing an agent provides no information on another. On the other hand the effectiveness of auditing increases as the correlation increases. This is obvious

for the case of perfect correlation since the principal only needs to audit a unique agent to acquire all the information.

\section{Model}

\subsection{Game sequence}

The following sequence is used in the paper to model information asymmetry:

- First, a complete contract is signed between a principal and risk averse agents that have limited liability so that the wages they receive must be non-negative. All players have the same information at this point. The contract specifies an audit strategy conditional on the agents' message, and a wage to be paid to each agent given the messages they sent to the principal and the result of the audits.

- Second, the agent performs a costless task.

- Third, each agent learns privately what his type is.

- Fourth, each agent sends a simultaneous message to the principal concerning his type.

- Fifth, the principal decides what subset of agents to audit.

- Sixth, payoffs are made to all players given the parameters of the contract signed initially. 


\subsection{Information structure}

Take the case of a company president who must handout year-end bonuses to her plant managers who possess private information that she values. In handing out the bonuses the president can rely entirely on her managers' reports or she can decide to invest in an audit. This information concerns the state of the world in which the managers are. There is no effort to be made to produce the task, so that there are no ex ante moral hazard problems. Moreover no agent knows its type before signing the contract so that there is no adverse selection problem either.

The type of problem at hand is known as ex post moral hazard (see Picard, 1996, Bond and Crocker, 1997, and Boyer, 2003) in the insurance literature, variance investigation (see Kaplan, 1975, Baiman and Demski, 1980, and Lambert, 1985) in the accounting literature and the regulation of monopolies with unknown costs (see Baron and Myerson, 1982, and Khalil, 1996) in the industrial organization literature. Others yet refer to this problem as one of moral hazard in reporting (Lambert, 2001). In general, we may say that this is a problem of costly state verification as in Townsend (1979) and Gale and Hellwig (1985).

Consider an organization composed of a principal (player 0) and $N$ agent (players 1 through $N)$. Agents are risk averse and their utility function over final wealth $U($.$) is twice differentiable.$ The principal offers each agent $n$ a take-it-or-leave-it contract; the game ends and the agent receives payoff $U(0)$ if he leaves it.

I restrict my attention to a symmetric organization in the sense that every player's task at a given level of the organization is the same. In other words, at any given level, every player is required to supervise the same number of underlings or the same number of machines.

After having accomplished his task each agent $n$ learns his type $\tau^{n}$ drawn from some discrete distribution $\Upsilon^{n}$ on domain $\left\{\tau_{1}^{n}, \ldots, \tau_{T}^{n}\right\}$ with $\tau_{t+1}^{n} \geq \tau_{t}^{n} \geq 0$. All agents are assumed to have the same number of types, but not necessarily the same set of types. In other words the cardinality of $\Upsilon^{n}$ is $T$ for all $n$ although $\Upsilon^{n} \neq \Upsilon^{n^{\prime}}$ when $n \neq n^{\prime}$. Without loss of generality, I model an agent's type as a monetary cost that enters his utility function so that $U_{\tau}^{\prime}()<$.0 .

Because every agent simultaneously and privately sends a message to the principal about his type, the message profile $m$ has $N$ elements, one for each agent. For any possible message profile, an audit policy is enacted. The audit policy reveals information $t_{j}$. Agent $n$ 's wage, noted $w^{n}\left(m, t_{j}\right)$, is then contingent on the message profile and on the information produced by the audits. Agent $n$ 's payoff is simply $U_{n}\left(w^{n}-\tau^{n}\right)$. Hence, for a given type $\tau^{n} \in \Upsilon^{n}\left\{\tau_{1}^{n}, \ldots, \tau_{T}^{n}\right\}$ the lowest payoff any agent may receive is $U_{n}\left(-\tau^{n}\right)$ because wages are restricted to be non-negative. 


\subsection{Contract design}

When information is correlated across agents, a new level of complexity is added to the problem, ${ }^{8}$ because of all the different combinations of agents and types. What is left to find is the number of variables that must be specified in the complete contract.

Auditing is costly to the principal; I restrict the auditing technology to yield constant returns to scale at any level in the hierarchy. Each audit costs some amount $c$. The audit technology is perfect in that it reveals correctly the agent's information. All audits are simultaneous. An audit policy specifies which agent or agents are to be audited as a function of the message profile.

Let $\pi_{\Omega^{i}}$ be the probability that some subset $\Omega^{i}$ of players is audited. Any subset $\Omega^{i}$ is then any of the $2^{N}$ elements of $\mathcal{P}(N)$, the power set of the $N$ agents, ${ }^{9}$. For example, if there are $N>8$ players, the probability that the subset composed of agents 1,5 and 8 is audited is given by $\pi_{\{1,5,8\}}$. Since auditing each individual agent $\operatorname{costs} c$, we need to know how many agents are in each subset. Let $\omega^{i}$ represent the cardinality of each subset $\Omega^{i}$. Given wages paid $w^{n}, n=1, \ldots, N$, and the audit policy, the objective function of a principal who would want to minimize the expected cost of the labor contract is

$$
E C=\underbrace{\sum_{n=1}^{N} w^{n}\left(m, t_{j}\right)}_{\text {wage function }}+\underbrace{c \sum_{i=1}^{2^{N}} \omega^{i} \pi_{\Omega^{i}}}_{\text {audit function }}
$$

The decision variables in this minimization problem will therefore be the wage function $w^{n}\left(m, t_{j}\right)$ as well as the auditing strategy $\pi_{\Omega^{i}}$, with $\sum_{i=1}^{2^{N}} \pi_{\Omega^{i}}=1$. Both will depend on the message profile received by the president and on the prior distribution of agent types. Clearly, truth-telling by all types of agents is achieved at the expense of some costly audits. At the margin, the principal would want to economize by reducing the probability of auditing. Unfortunately, reducing the probability of performing an audit has impacts on the principal's expected payoffs.

In my model, truth-telling is obtained at a smaller cost than in McAfee and McMillan (1995) and Melumad et al. (1998). Because agents compete over the information they have to transmit and because the agents' information is correlated, truth-telling is thus obtained through the efficient design of a compensation contract and of an audit policy that takes into account this correlation.

\subsubsection{Number of types and audit policies}

Each agent $n \in N$ observes his type $\tau^{n}=\tau_{k}^{n} \in \Upsilon^{n}\left\{\tau_{1}^{n}, \ldots, \tau_{T}^{n}\right\}$, where, without loss of generality, $\tau_{k}^{n} \geq \tau_{k-1}^{n}$. There are thus $T^{N}$ type profiles in the organization since I assumed earlier that the

\footnotetext{
${ }^{8}$ See Krasa and Villamil (1994) for example.

${ }^{9}$ Recall that the power set is the set of all possible subsets, including the complete set and the empty set. With $N$ players, there are $2^{N}$ possible subsets.
} 
cardinality of $\Upsilon^{n}$ is $T \forall n \in N$. Each agent then sends message $m^{n}$ to the principal.

The audit policy chosen by the principal specifies which subset of agents is to be audited conditional on the message profile $m$ sent by all the agents. The message profile thus has $N$ elements. Using the Revelation Principle I can restrict my attention to truthful messages (i.e., $\left.m^{n} \in \Upsilon\left\{\tau_{1}^{n}, \ldots, \tau_{T}^{n}\right\}\right)$. With simultaneous audits, an audit policy then specifies a set of probabilities $\pi_{\eta}$ such that only the subset $\eta$ of agents will be audited, with $\sum_{\eta \varepsilon \mathcal{P}(N)} \pi_{\eta}=1$. Given there are $\mathcal{P}(N)=2^{N}$ possible subsets of managers, we only need $2^{N}-1$ audit probabilities since audit probabilities must sum to one.

For a given type profile there are thus $K=2^{N}-1$ audit probabilities to be determined. Given there are $J=T^{N}$ type profiles, the complete contract must specify $J K=T^{N}\left(2^{N}-1\right)$ audit policies.

\subsubsection{Number of wages}

The principal compensates each agent using a wage $w^{i}$ that is contingent on the messages sent to her by the agents and on the result of performed audits. A wage to agent $i$ contingent on the profile of messages $m$ and on the information $a$ produced by the audits conducted on the subset $\eta$ of managers is noted $w_{\eta, a}^{i}(m)$.

Let us count the number of wages that must be specified following a message profile $m$. For each subset $\eta$ of audited agents, there are $A_{|n|}$ possible results. The number of subsets in $\mathcal{P}(N)$ that have $k=|\eta|$ elements is $\left(\begin{array}{c}N \\ k\end{array}\right)$. For a given message profile, there are therefore $L=1+\sum_{k=1}^{N}\left(\begin{array}{c}N \\ k\end{array}\right) T^{k}=$ $(T+1)^{N}$ possible contingencies to consider. ${ }^{10}$ Given there are $J=T^{N}$ type profiles for which $N$ wages must be specified, the complete contract must specify $N J L=N T^{N}(T+1)^{N}$ wages.

\subsubsection{The complete contract}

The complete contract in this model is composed of an audit function and of a wage function. The audit function has $T^{N}\left(2^{N}-1\right)$ elements whereas the wage function has $N T^{N}(T+1)^{N}$ elements. As a result, in an organization composed of $N$ agents who can each be any of $T$ possible types, a complete contract $\mathcal{C}$ must specify $C(T, N)=T^{N}\left[\left(2^{N}-1\right)+N(T+1)^{N}\right]$ parameters. ${ }^{11}$

In the supposedly simple $2 \times 2$-CASE, that of two agents $(N=2)$ with two types $(T=2)$, the complete contract must specify $C(2,2)=2^{2}\left[\left(2^{2}-1\right)+2(2+1)^{2}\right]=4(3+2 \cdot 9)=84$ vari-

\footnotetext{
${ }^{10}$ Another way to get that result is to augment the type set of each agent by a "null" type which represents the ex post type of an agent that has not been audited. Then, either the agent is audited, with $T$ possible outcomes, or he is not audited and we say that he has the null type. There are then $(T+1)^{N}$ possible outcomes to the audits.

${ }^{11}$ One can reduce the number of parameters assuming the symmetry of agent types and Nash implementation. This does not affect the results of the paper, only the calculation of the number of parameters. See Boyer and Gonzalez (2004) for a discussion of the symmetry in the agents' types and of Nash implementation.
} 
ables. With six agents each having six types, the complete contract must specify $C(6,6)=$ $6^{6}\left[\left(2^{6}-1\right)+6(6+1)^{6}\right]=32,937,129,792$ variables. The following table computes the number of variables that need to be specified in a complete contract as a function of the number of types $T$ and of the number of agents $N$.

\begin{tabular}{|c|c|c|c|c|c|c|c|}
\hline \multirow[t]{3}{*}{$\mathcal{C}$} & \multicolumn{7}{|c|}{$T$} \\
\hline & & 1 & 2 & 3 & 4 & 5 & 6 \\
\hline & 1 & 3 & 8 & 15 & 24 & 35 & 48 \\
\hline \multirow[t]{5}{*}{$N$} & 2 & 11 & 84 & 315 & 848 & 1,875 & 3,636 \\
\hline & 3 & 31 & 704 & 5,373 & 24,448 & 81,875 & 223,776 \\
\hline & 4 & 79 & 5,424 & 84,159 & 643,840 & $3,249,375$ & $12,466,224$ \\
\hline & 5 & 191 & 39,872 & $1,251,693$ & $16,031,744$ & $121,596,875$ & $653,697,216$ \\
\hline & 6 & 447 & 283,968 & $17,961,831$ & $384,258,048$ & $4,374,984,375$ & $32,937,129,792$ \\
\hline $\begin{array}{l}\text { The e } \\
\text { as a } \\
\text { The }\end{array}$ & & tion & $\begin{array}{l}\text { the numb } \\
\text { f the num } \\
\text { are calcul }\end{array}$ & $\begin{array}{l}\text { er of paramet } \\
\text { ber of agents } \\
\text { ted using the }\end{array}$ & $\begin{array}{l}\text { ers that need } t \\
(N) \text { and of the } \\
\text { formula } C(T,\end{array}$ & $\begin{array}{l}\text { o be specified in } \\
\text { number of types } \\
N)=T^{N}\left[\left(2^{N}-\right.\right.\end{array}$ & $\begin{array}{l}\text { a complete contra } \\
(T) \text { of each agen } \\
\text { 1) }+N(T+1)^{N}\end{array}$ \\
\hline
\end{tabular}

It is interesting to note that the complexity of the complete contract increases faster as the number of managers increases than when the number of types increases. For example, it is relatively less complex to design a contract when there are four agents that may be any of six types $(N=4$, $T=6)$ than to design a contract when there are five agents than can be of only four types $(N=5$, $T=4)$ or a contract with six agents and three types $(N=6, T=3)$ or even a contract with eight agents and two types $(N=8, T=2)$. This gives us a first glimpse as to why hierarchies are better at completing contracts. We will come back to this later.

\subsection{Complete contract complexity}

It is clear in Table 1 that the number of parameters that need to be specified in a complete contract increases very rapidly as the number of possible types and of agents increases. What I shall call the complexity of a contract will merely be the number of variables that need to be specified. As stated in the introduction, I deviate from the computational economic view of complexity as presented by Anderlini and Felli (1994, 1999). As a result I am, as Dye (1985), enumerating the contingencies that the contract must consider. 


\section{Hierarchies}

An interesting implication of contract complexity is that it gives a rationale for hierarchies when players have a limited computing ability such as in Geanakoplos and Milgrom (1990) Radner (1993), Melumad et al. (1997), Segal (1999) and Orbay (2002). In particular, I will assume that a player's ability is defined by the number of contract parameters that he is able to keep track of. I shall first present three examples of hierarchies, then I will present more general results. In all cases, I will assume a symmetric organization so that any player at a given level of the organization is faced with the same task complexity.

\subsection{Three examples}

\subsubsection{Example 1}

Suppose that some individuals have the intellectual capability of managing at most $\underline{C}=40,000$ variables (low-ability), while others have the intellectual capability of managing $\bar{C}=2,250,000$ variables (high-ability). If each machine is operated by one person (let's call this person a worker) and if machines can either spit out a good quality widget or a bad quality widget, then any worker may be of only two types: Good or Bad.

From the formula $C(T, N)=T^{N}\left[\left(2^{N}-1\right)+N(T+1)^{N}\right]$, the maximum number of workers any low ability individual can supervise is five, since $C(2,5)=39,872<40,000=\underline{C}$. This means that if the organization has ten machines, two low-ability individuals need to be hired to manage these ten workers. Each manager will then be any of $T^{N}=2^{5}=32$ types because each supervises five workers who can be of two types. This means that the company president will need to have the intellectual capacity to handle a contract that has $C(32,2)=32^{2}\left[\left(2^{2}-1\right)+2(32+1)^{2}\right]=$ 2, 233, 344 variables. A high-ability individual is capable of handling this.

It thus becomes optimal to have two low-ability individuals be the managers, and the highability individual be the company president. This pyramidal organization allows to have a complete contract so that all the information is revealed. In contrast, if the president wanted to oversee all workers himself, he would need to have the intellectual ability to manage $C(2,10)=605,709,312$ variables, which is much greater than the intellectual ability of managing 2, 233, 344 variables when a three-level hierarchy is used. As a result, this organization (let us call it Organization 1 in Figure 1) has ten workers at level-0, two level-1 managers with ability $\underline{C}=40,000$ and one president with 
ability $\bar{C}=2,250,000$.

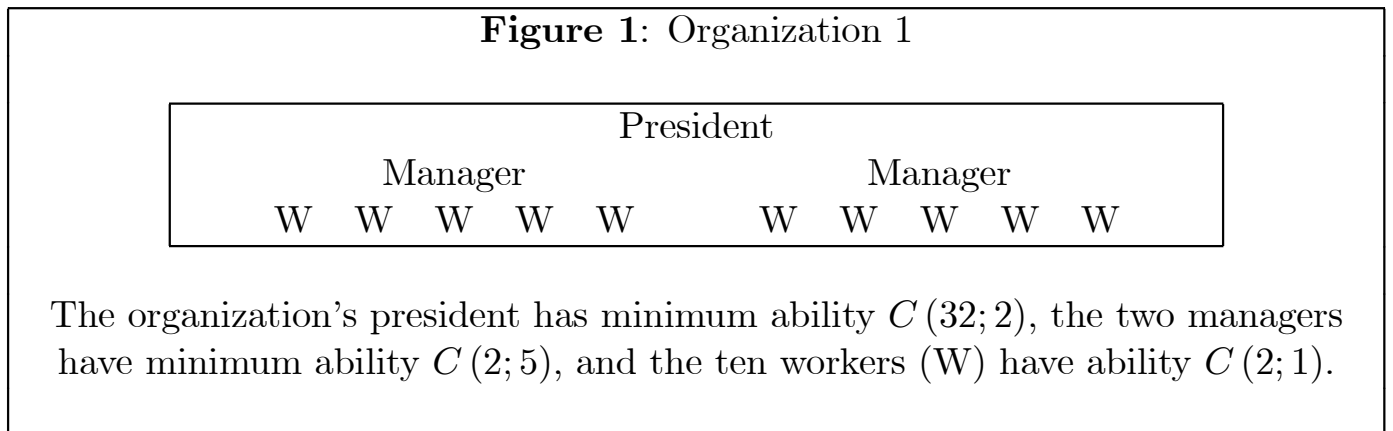

\subsubsection{Example 2}

Suppose now that the organization triples its work force so that there are now 30 workers in the organization. Again each worker oversees an unique machine that produces either a good widget or a bad widget, so that each worker's type can be either of two types.

From example 1, we know that six $C(2,5)$-ability managers are needed to supervise these 30 workers. The organization then needs three $C(32,2)$-ability managers to supervise the six $C(2,5)$-ability managers. Each $C(32,2)$-ability managers may then be any of $T^{N}=2^{10}=1024$ types, because their type depends only on the workers' set of types. With three $C(32,2)$-ability managers, the company president will need to have the intellectual ability to handle a contract that has $C(1024,3)$ variables. Is this optimal?

Suppose instead that the company president decides that he wants to oversee the six $C(2,5)$ ability managers directly. Because each $C(2,5)$ manager can be any of 32 types, the president's intellectual ability must be at least equal to $C(32,6)$, which is greater than $C(1024,3)$. If he wants to oversee the workers directly, his intellectual ability must $C(2,30)$, which is again greater than $C(1024,3) .{ }^{12}$

Finally, instead of hiring six $C(2,5)$-ability managers to oversee the workers, the company president may choose to hire three $C(2,10)$-ability managers. These $C(2,10)$-ability managers may be any of $2^{10}=1024$ types. The company president then needs to have the intellectual ability to handle a contract that has has $C(1024,3)$ variables. This is the same required ability than in the previous three layer organization. Based only on his computing ability, the company president

\footnotetext{
${ }^{12}$ The reader may verify that $C(1024,3)=3,469 E+18, C(32,6)=8,320 E+18$, and $C(2,30)=6,632 E+24$.
} 
should then be indifferent between Organization 2.1 and Organization 2.2 in Figure 2 below.

\section{Figure 2.}

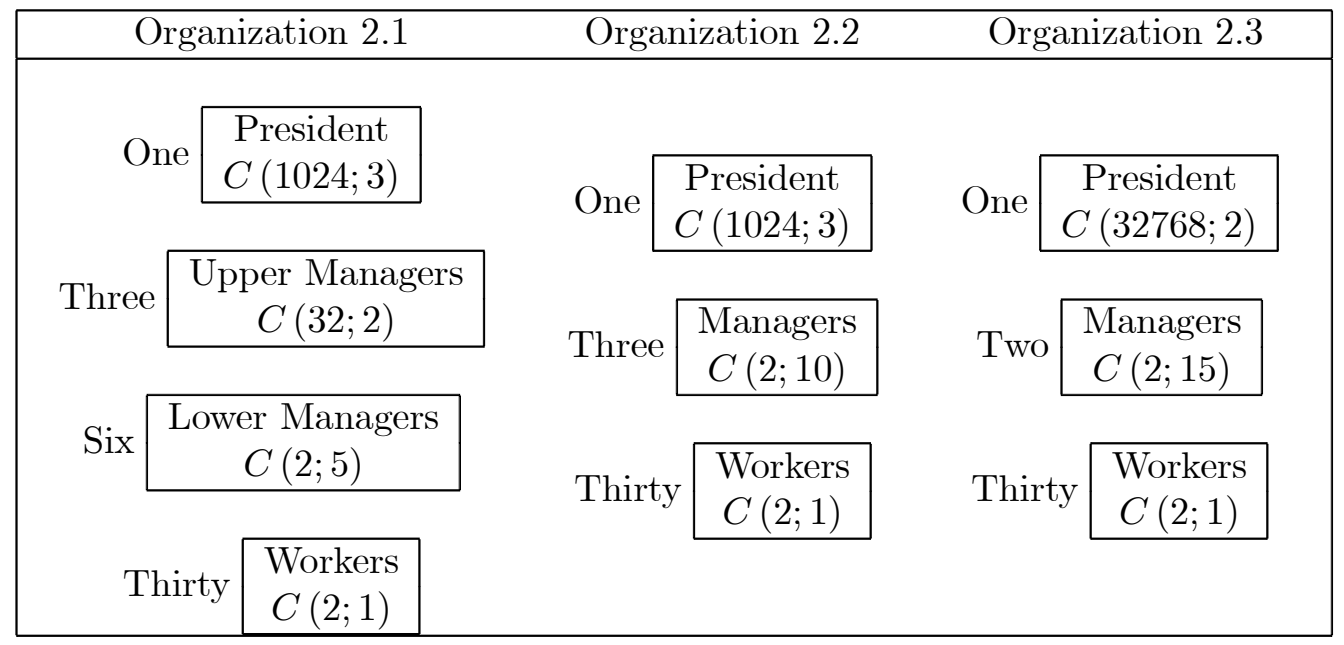

Three hierarchies for one organization with the required minimum competence at each level.

The three managers in Organization 2.2 require an intellectual ability of $C(2,10)$; this ability is greater than the one required of the upper managers in Organization 2.1, which was $C(32,2)$. The choice of the company president between the two types of organizations will then depend on the availability of $C(2,10)$-ability managers on the labor market, and on the relative costs (the wages that need to be paid to the managers) of each organizational structure.

Assuming that managers of all abilities are available on the labor market, an absence-of-arbitrage argument allows me to state that, in equilibrium, the president must be indifferent between organizations 2.1 and 2.2. As a result, the cost of hiring three $C(2 ; 10)$ managers must be the same as hiring three $C(32,2)$ managers and six $C(2,5)$ managers. Thus, the managers' salary must be proportional to their computing ability relative to the other agents'.

Suppose a third organization (Organization 2.3) were possible in which the number of managers is only two, but each have the intellectual ability to manage 15 workers each. Their intellectual ability is then $C(2,15)$. The company president then needs to have an ability at least equal to $C\left(2^{15}, 2\right)$ to be able to supervise the two $C(2,15)$-ability managers. The reader will verify that $C\left(2^{10}, 3\right)<C\left(2^{15}, 2\right)$ so that it is quite possible that the company president will not be able to implement Organization 2.3 if a complete contract is required and her ability is limited to handling merely $C\left(2^{10}, 3\right)$ variables.

As a result, if the company president's ability is limited to $C^{P}=C(1024,3)$ and the managers' ability is limited to $C(32 ; 2)$, then the organization will need to have four levels in its hierarchy: thirty workers, six lower (level-1) managers, three upper (level-2) managers and one president. This 
means that Organization 2.1 should be observed in the economy. It is interesting to note that in all three organizations, the minimum ability that is needed increases with the level in the hierarchy. This result could not be predicted by Geanakoplos and Milgrom (1980).

If we look at Organization 2.1 and compare it Organization 1 presented in the previous example, it is worth noting that an increase in the number of workers from 10 to 30 has three interesting implications as to the shape of the organization.

1. The number of layers in the organization increases (from 3 to 4);

2. Even though the number of workers is three times as high in Organization 2.1 than in Organization 1 , the number of middle managers (managers that lie between the president and the workers) has more than tripled (from 2 to 9);

3. The president of Organization 2.1 needs to be more qualified than the president of Organization 1 so that she must, presumably, command a higher salary.

\subsubsection{Example 3}

Let us now set the number of workers in the organization to 210. Suppose managers (excluding the president) must be divided over three levels. How should the president divide the managers to minimize the sum of the computing abilities necessary to complete the contract?

Let $N_{0}$ be the number of workers than need supervision. Let $N_{\mu}$ represent the number of managers at level $\mu$, with $\mu=1, \ldots, M$. The president sits on level $M$ so that $N_{M}=1$. Let $S_{\mu}$ represent the number of individuals at level $\mu-1$ that are being supervised by each individual at level $\mu$, with $\mu \geq 1$. The number of level $\mu$ managers is then $N_{\mu}=\frac{N_{\mu-1}}{S_{\mu}}=N_{\mu+1} \times S_{\mu+1}$, for $\mu=1, \ldots, M-1$. It clearly follows that the product of all supervised individuals must be equal to the number of workers: $\Pi_{\mu} S_{\mu}=N_{0} \cdot{ }^{13}$ The total number of managers, including the president, is given by $\Sigma_{\mu=1}^{M} N_{\mu}=\Sigma_{\mu=2}^{M} \Pi_{\eta=\mu}^{M} S_{\eta} \cdot{ }^{14}$

Because the organization is required to have only three levels (so that $M=4$ ), we need to find the $S_{\mu}$ such that $\Pi_{\mu=1}^{4} S_{\mu}=N_{0}$. When $N_{0}=210$, it is clear that the $S_{\mu}$ must be $2,3,5,7$ since $2 \times 3 \times 5 \times 7=210$. The question that remains is how these supervised individuals are distributed

\footnotetext{
${ }^{13}$ To see why, rewrite $N_{\mu}=\frac{N_{\mu-1}}{S_{n}}$ as $S_{\mu}=\frac{N_{\mu-1}}{N_{\mu}}$. The product over all $S_{\mu}$ is then $\Pi_{\mu} S_{\mu}=\frac{N_{M-1}}{N_{M}} \times \frac{N_{M-2}}{N_{M-1}} \times \ldots \times$ $\frac{N_{n-1}}{N_{n}} \times \frac{N_{n-2}}{N_{n-1}} \times \ldots \times \frac{N_{1}}{N_{2}} \times \frac{N_{0}}{N_{1}}$. Simplifying, we are left with $\Pi_{\mu} S_{\mu}=\frac{N_{0}}{N_{M}}$. Since $N_{M}=1$ (the president), it follows that $\Pi_{\mu} S_{\mu}=N_{0}$.

${ }^{14}$ To see why, substitute for $N_{\mu}=\frac{N_{\mu-1}}{S_{\mu}}$ and expand the sum to yield $\Sigma_{\mu=1}^{M} N_{\mu}=\Sigma_{\mu=1}^{M-1} \frac{N_{\mu-1}}{S_{\mu}}=\frac{N_{0}}{S_{1}}+\frac{N_{1}}{S_{2}}+\ldots+\frac{N_{M-1}}{S_{M}}$. Substituting for $N_{1}=\frac{N_{0}}{S_{1}}$, and all the $N_{\mu}=\frac{N_{0}}{\Pi_{\eta=1}^{\mu} S_{\eta}}$ yields $\Sigma_{\mu=1}^{M} \frac{N_{\mu-1}}{S_{\mu}}=\frac{N_{0}}{S_{1}}+\frac{N_{0}}{S_{1} S_{2}}+\frac{N_{0}}{S_{1} S_{2} S_{3}}+\ldots+\frac{N_{0}}{S_{1} S_{2} \ldots S_{M-1}}+\frac{N_{0}}{\Pi_{\eta=1}^{M} S_{\eta}}$. We know that $\frac{N_{0}}{\Pi_{\eta=1}^{M} S_{\eta}}=1$. The number of managers is then given by $\Sigma_{\mu=1}^{M} N_{\mu}=\Sigma_{\mu=2}^{M} \Pi_{\eta=\mu}^{M} S_{\eta}$.
} 
in the hierarchy so as to minimize the computing costs. Let us start with the upper layer, $N_{3}$, and work our way down.

Looking at level 3 , the president has a choice of supervising $S_{M}=$

- seven managers that can take on $2^{30}$ types,

- five managers that can take on $2^{42}$ types,

- three managers that can take on $2^{70}$ types,

- two managers that can take on $2^{105}$ types.

The president's computing ability needed in each case is $C\left(2^{30}, 7\right), C\left(2^{42}, 5\right), C\left(2^{70}, 3\right)$ and $C\left(2^{105}, 2\right)$. The reader can verify that $C\left(2^{30}, 7\right)>C\left(2^{42}, 5\right)>C\left(2^{70}, 3\right)>C\left(2^{105}, 2\right)$. As a result, the company president will choose to have only $S_{M}=2$ managers to supervise, albeit of any of $2^{105}$ types. The president's ability is then $C\left(2^{105}, 2\right)$. This means that there are $N_{3}=N_{M} S_{M}=2$ level-3 managers.

Looking at layer 2, each level 3 managers have a choice of supervising $S_{3}=$

- seven managers that can take on $2^{15}$ types,

- five managers that can take on $2^{21}$ types,

- three managers that can take on $2^{35}$ types.

The computing power needed in each case is $C\left(2^{15}, 7\right), C\left(2^{21}, 5\right)$ and $C\left(2^{35}, 3\right)$, with $C\left(2^{15}, 7\right)>$ $C\left(2^{21}, 5\right)>C\left(2^{35}, 3\right)$. Each of the $N_{3}=2$ level-3 managers therefore needs to supervise $S_{3}=3$ level-2 managers. This requires ability $C\left(2^{25}, 3\right)$. There are thus $N_{2}=N_{3} S_{3}=6$ level-2 managers.

Looking at layer 1, each level 2 managers have a choice of supervising $S_{2}=$

- seven managers that can take on $2^{5}$ types,

- five managers that can take on $2^{7}$ types.

The computing power needed in each case is $C\left(2^{5}, 7\right)$ and $C\left(2^{7}, 5\right)$, with $C\left(2^{5}, 7\right)>C\left(2^{7}, 5\right)$. Each of the $N_{2}=6$ level-2 managers needs to have ability $C\left(2^{7}, 5\right)$ to supervise $S_{2}=5$ level-1 managers. There are therefore $N_{1}=N_{2} S_{2}=30$ level-1 managers.

Finally, looking at the workers, each of the $N_{1}=30$ level-1 managers will supervise $S_{1}=7$ workers, which requires ability $C(2,7)$. Or course, there are $N_{0}=S_{1} N_{1}=210$ workers who each supervise one machine that may produce a good quality or a bad quality widget. 
The total computing ability of the organization is therefore

$$
\mathcal{A}^{*}=C\left(2^{105}, 2\right)+2 \times C\left(2^{25}, 3\right)+6 \times C\left(2^{7}, 5\right)+30 \times C(2,7)
$$

One can verify that this structure is the one that minimizes the necessary abilities in the organization given the requirement of having $M=4$, most of it being driven by the first term: $C\left(2^{105}, 2\right) .{ }^{15}$ It follows that the organization has the following structure: one president at level 4 , two senior vice presidents at level 3, six junior vice-presidents at level 2, thirty managers at level 1 and 210 workers at level 0 .

\subsection{Optimal structure}

The computational cost of acquiring and transferring information is but only one aspect of the cost encountered by the organization's president. He must also consider the cost of giving wages to the organization's middle managers. For a given managerial wage structure the president will minimize the organization's wage cost by finding a hierarchical structure that utilizes everyone's computing ability to the fullest. Under this condition, an organization should also choose a structure that necessitates the lowest computational ability.

\subsubsection{Minimizing the computing cost}

As before, assume that the president is restricted to use a symmetric structure in the sense that every manager at a given level must have the same number of tasks to oversee. Assume the workers may take on $T_{0}$ types, so that the two-level hierarchy necessitates an ability equal to $C\left(T_{0}, N_{0}\right)$, where $N_{0}$ is the number of workers in the organization. ${ }^{16}$ I want to find a way for the principal to minimize his computational cost. His programme is then to find the number of level $\mu$ managers,

\footnotetext{
${ }^{15}$ For example, let us compare it with

$$
\mathcal{A}_{1}=C\left(2^{70}, 3\right)+3 \times C\left(2^{35}, 2\right)+6 \times C\left(2^{7}, 5\right)+30 \times C(2,7)
$$

${ }^{16}$ Because of symmetry, the number of managers at the different levels $\left(N_{1}, N_{2}, N_{3}, \ldots, N_{M}\right)$ is defined so that $\Pi_{\mu=1}^{M} N_{\mu}=N_{W}$.
} 
$N_{\mu}$, each having $T_{\mu}$ types, that minimizes

$$
\begin{aligned}
\mathcal{A}= & C\left(T^{N_{0} / S_{M}}, S_{M}\right)+N_{M-1} \times C\left(T^{N_{0} / S_{M} S_{M-1}}, S_{M-1}\right) \\
& +N_{M-2} \times C\left(T^{N_{0} / S_{M} S_{M-1} S_{M-2}}, S_{M-2}\right) \\
& +N_{M-3} \times C\left(T^{N_{0} / S_{M} S_{M-1} S_{M-2} S_{M-3}}, S_{M-3}\right)+\ldots \\
= & C\left(T^{N_{0} / S_{M}}, S_{M}\right)+N_{M} S_{M} \times C\left(T^{N_{0} / S_{M} S_{M-1}}, S_{M-1}\right) \\
& +N_{M} S_{M} S_{M-1} \times C\left(T^{N_{0} / S_{M} S_{M-1} S_{M-2}, S_{M-2}}\right) \\
& +N_{M} S_{M} S_{M-1} S_{M-2} \times C\left(T^{N_{0} / S_{M} S_{M-1} S_{M-2} S_{M-3}, S_{M-3}}\right)+\ldots \\
= & C\left(T^{N_{0} / S_{M}}, S_{M}\right)+S_{M} \times C\left(T^{N_{0} / S_{M} S_{M-1}}, S_{M-1}\right) \\
& +S_{M} S_{M-1} \times C\left(T^{\left.N_{0} / S_{M} S_{M-1} S_{M-2}, S_{M-2}\right)}\right. \\
& +S_{M} S_{M-1} S_{M-2} \times C\left(T^{N_{0} / S_{M} S_{M-1} S_{M-2} S_{M-3}}, S_{M-3}\right)+\ldots
\end{aligned}
$$

More concisely, I can rewrite the minimization problem as

$$
\min _{S_{M}, \ldots, S_{1}} \mathcal{A}=\sum_{j=1}^{M} \Gamma_{j} C\left(T^{N_{0} \Delta_{j}}, S_{j}\right)
$$

where $\Gamma_{j}=\left(\frac{\prod_{k=2}^{M} S_{k}}{\prod_{k=2}^{M-j+1} S_{k}}\right)$ and $\Delta_{j}=\left(\frac{\prod_{k=2}^{M-j} S_{k}}{\prod_{k=1}^{M} S_{k}}\right)$, subject to $\prod_{j=1}^{M} S_{j}=N_{0} \cdot{ }^{17}$ By minimizing the total computational cost in his organization the president is able to higher managers that command a lower compensation because they are less skilled

\subsubsection{Minimizing wage cost}

Instead of minimizing the computational cost in the organization, the president may instead decide to minimize the total wages that must be given to all agents in the organization. Suppose that on the labor market a manager of quality $C_{i}\left(T_{i}, N_{i}\right)$ commands a wage of $w\left[C_{i}\right]$. The organization's president will then choose the structure that minimizes the total wage cost. In other words, the

\footnotetext{
${ }^{17}$ Or written completely,

$$
\begin{aligned}
\min _{S_{M}, \ldots, S_{1}} A & =\sum_{j=1}^{M}\left(\frac{\prod_{k=2}^{M} S_{k}}{\prod_{k=2}^{M-j+1} S_{k}}\right) C\left(T^{N_{0}\left(\frac{\prod_{k=2}^{M-j} S_{k}}{\prod_{k=1}^{M} S_{k}}\right)}, S_{j}\right) \\
\text { s.t. } \quad \prod_{j=1}^{M} S_{j} & =N_{0}
\end{aligned}
$$
}


optimal structure will be the one that minimizes

$$
\min _{S_{M}, \ldots, S_{1}} \mathcal{W}=\sum_{j=1}^{M} \Gamma_{j} w_{j}\left[C\left(T^{N_{0} \Delta_{j}}, S_{j}\right)\right]
$$

where $\Gamma_{j}=\left(\frac{\prod_{k=2}^{M} S_{k}}{\prod_{k=2}^{M-j+1} S_{k}}\right)$ and $\Delta_{j}=\left(\frac{\prod_{k=2}^{M-j} S_{k}}{\prod_{k=1}^{M} S_{k}}\right)$, subject to $\prod_{j=1}^{M} S_{j}=N_{0}$. The only difference between the two approaches is that one focuses on the computation cost whereas the other focuses on the wage cost.

\subsubsection{Wages and abilities}

The two approaches can be combined by saying that the organization's president will want to minimize the computational cost while keeping wages lower than some amount. In other words, minimizing the function $\mathcal{A}$ while keeping $\mathcal{W}$ smaller than some $\bar{W}$.

The results of Geanakoplos and Milgrom (1991) is related to this limited ability of handling complicated contracts. Hierarchies are an efficient mechanism of information transmission when individuals are limited in their ability to manage complex tasks. The introduction of a hierarchy in an organization allows to have lower management monitor an optimal number of tasks, and have upper management monitor an optimal number of lower managers. The number of echelons in the hierarchy then depends on the individuals' ability to manage the many different provisions of the complete contract.

\section{Applications, implementation and discussion}

\subsection{Information and wages}

Returning our attention to the numbers presented in Table 1, we note an apparent trade-off between the number of agents and the number of types. This trade-off exists even if contract complexity rises faster with the number of agents than with the number of types. Such a trade-off implies that organizations may prefer to have less agents that oversee more machines than to have more agents that oversee less machines.

For example, suppose that machines can either produce a good quality widget or a bad quality widget. A manager who oversees the quality of an unique machine and who must report such a quality to the president can make only two types of report: Bad or Good. A manager who oversee two machines can make four types of report: Bad-Bad, Bad-Good, Good-Bad, Good-Good. A manager that oversees three machines can make eight types of reports: Bad-Bad-Bad, Bad-BadGood, Bad-Good-Bad, Good-Bad-Bad, Bad-Good-Good, Good-Bad-Good, Good-Good-Bad, and 
Good-Good-Good. In fact, when a manager must supervise $G$ machines that can either produce a good quality widget or a bad quality widget, it is easy to show that there are $T=2^{G}$ reports that can be made to the president. This means that the number of types of a manager will depend on the number of machines he needs to supervise. The question then becomes whether it is better to have $\frac{N}{x}$ managers overseeing the $G$ machines or to have $N$ agents overseeing $\frac{G}{x}$ machines.

From a point of view of complexity, it will always be better to reduce the number of agents to the minimum as we can see in Table 1. This reduction in complexity must, however, be weighted against the higher wage that needs to be paid to the manager. As the number of managers is increased, the president is better equipped to evaluate the performance of the different managers since she receives more information. And because the president has more information, it may allow her to reduce the wage paid. As a result, although the complete contract is more complex when there are more managers, the president may prefers it because it allows her to extract more information.

Take the extreme case of two machines whose quality is perfectly correlated. If one manager oversees all machines, the manager can send three reports. With three types and one manager, this gives us 15 parameters to specify in the complete contract. A wage greater than the reservation wage must then be paid and costly audits need to be conducted periodically. If two managers oversee one machine each, the president can achieve full surplus extraction by paying managers their reservation wage and by never auditing because the manager types (widget quality) are perfectly correlated. In fact, as in Boyer and González (2004), the greater the correlation between the different types (whether positive or negative), the less costly it is to induce truth-telling because audits are conducted with lower frequency and wages are smaller. The complexity of the contract is not affected, however, by the amount of correlation between the agents' information.

An organization must then find the right balance between complexity and information. As the complexity of the contract increases, more information is extracted so that lower wages can be paid and the audit cost is incurred less often.

\subsection{Task complexity}

In all examples presented so far the task that is required of workers in the organizations is quite simple: Either the machine produced a high quality or a low quality widget. In reality, the tasks of workers are much more complicated than that. One may then wonder what happens to the structure of the organization when the workers' task becomes more complex? Task complexity may be measured by the number of types each agent may be so that the question then becomes what happens to the organizational form when the number of possible types increases? 
CLAIM. The complexity of the complete contract rises faster as we climb the corporate ladder.

The first thing to note is that the complexity of the complete contract increases in both the number of agents and the number of possible types; both $\frac{\Delta C}{\Delta T}$ and $\frac{\Delta C}{\Delta N}$ are positive. Second, we can also see that $\frac{\Delta^{2} C}{\Delta T \Delta N}>0$. In fact, we can calculate ${ }^{18}$

$$
\begin{aligned}
\frac{\partial^{2} C}{\partial T \partial N}= & N T^{N-1}\left[\begin{array}{c}
(\ln T)\left(2^{N}-1\right)+2^{N}(\ln 2) \\
+(T+1)^{N}((\ln T) N+1+N(\ln (T+1))
\end{array}\right] \\
& +T^{N}\left[\begin{array}{c}
\frac{1}{T}\left(2^{N}-1\right)+N(T+1)^{N-1}((\ln T) N+1+N(\ln (T+1)) \\
+N(T+1)^{N}\left(\frac{1}{T}+\frac{1}{T+1}\right)
\end{array}\right]
\end{aligned}
$$

which is clearly positive since $T \geq 1$ and $N \geq 1$. As a result, the marginal increase in the complexity of the contract as the task becomes more complex increases with the number of agents. This means that the ability required of managers who sit at the upper echelons will need to increase much faster than the ability that is required of lower echelon managers.

If managers are already at their maximum ability in terms of the number of agents to supervise and the number of tasks that each agent is required to do, then an increase in the complexity of the tasks that is required of agents will induce the hiring of more managers. Although this is obvious because of the definition of limited ability, what is not as obvious is that the number of upper managers will increase faster than the number of lower managers.

Suppose an organization has $N_{0}$ workers that can be any of $T_{0}$ possible types. The organization is restricted to have $\mathrm{M}$ layers so that there is one president at level $N_{M}$. The $N_{1}$ level-1 managers, who supervise $S_{1}=\frac{N_{0}}{N_{1}}$ workers each, need to have a computing ability at least equal to $C\left(T_{0}, S_{1}\right)$. The $N_{2}$ level-2 managers, who supervise the $S_{2}=\frac{N_{1}}{N_{2}}$ level-1 managers must have computing ability at least equal to $C\left(T_{1}, S_{2}\right)$, where $T_{1}=T_{0}^{N_{0}}$. The $N_{3}$ level-3 managers, who supervise the $S_{3}=\frac{N_{2}}{N_{3}}$ level-2 managers must have computing ability at least equal to $C\left(T_{2}, S_{3}\right)$, where $T_{2}=T_{1}^{N_{1}}=T_{0}^{N_{0} N_{1}}$. In general, the $N_{\mu}$ level- $\mu$ managers, who supervise the $S_{\mu}=\frac{N_{\mu-1}}{N_{\mu}}$ level- $\mu-1$ managers must have computing ability at least equal to $C\left(T_{\mu-1}, S_{\mu}\right)$, where $T_{\mu}=T_{\mu-1}^{N_{\mu-1}}=T_{0}^{N_{0} N_{1} \cdots N_{\mu-1}}$. Let us look at what happens to task complexity between levels 1 and 2 .

Say complexity of the task of the workers goes from $T_{0}$ to $T_{0}+1$. The computing ability of the level-1 managers then goes from $C\left(T_{0}, S_{1}\right)$ to $C\left(T_{0}+1, S_{1}\right)$. Using the formula given in Table 1 , the rate of increase in the required ability, assuming the number of managers does not change, is

$$
\frac{C\left(T_{0}+1, S_{1}\right)}{C\left(T_{0}, S_{1}\right)}=\frac{\left(T_{0}+1\right)^{S_{1}}\left[\left(2^{S_{1}}-1\right)+S_{1}\left(T_{0}+1+1\right)^{S_{1}}\right]}{T_{0}^{S_{1}}\left[\left(2^{S_{1}}-1\right)+S_{1}\left(T_{0}+1\right)^{S_{1}}\right]}
$$

\footnotetext{
${ }^{18}$ It is clear that this equation does not make sense technically since the number of types and the number of agents is not continuous. Nevertheless, the point I want to make is the same.
} 
or, put differently,

$$
\frac{C\left(T_{0}+1, S_{1}\right)}{C\left(T_{0}, S_{1}\right)}=\left(\frac{T_{0}+1}{T_{0}}\right)^{S_{1}}\left(\frac{\left(2^{S_{1}}-1\right)+S_{1}\left(T_{0}+1+1\right)^{S_{1}}}{\left(2^{S_{1}}-1\right)+S_{1}\left(T_{0}+1\right)^{S_{1}}}\right)
$$

On the other hand, the minimum computing ability of level-2 managers goes from $C\left(T_{0}^{N_{0}}, S_{2}\right)$ to $C\left(\left(T_{0}+1\right)^{N_{0}}, S_{2}\right)$. We then have

$$
\frac{C\left(\left(T_{0}+1\right)^{N_{0}}, S_{2}\right)}{C\left(T_{0}^{N_{0}}, S_{2}\right)}=\left(\frac{T_{0}+1}{T_{0}}\right)^{N_{0} S_{2}}\left(\frac{\left(2^{S_{2}}-1\right)+S_{2}\left(\left(T_{0}+1\right)^{N_{0}}+1\right)^{S_{2}}}{\left(2^{S_{2}}-1\right)+S_{2}\left(T_{0}^{N_{0}}+1\right)^{S_{2}}}\right)
$$

I want to show that the rate of increase in equation 2 is greater than the rate of increase in equation 1. First note that $\left(\frac{T_{0}+1}{T_{0}}\right)^{S_{1}}<\left(\frac{T_{0}+1}{T_{0}}\right)^{N_{0} S_{2}}$ since $N_{0} S_{2}-S_{1}=N_{0}\left(S_{2}-\frac{1}{N_{1}}\right)>0$ because $S_{2}>1>\frac{1}{N_{1}}$. I then only need to show that

$$
\frac{\left(2^{S_{1}}-1\right)+S_{1}\left(T_{0}+1+1\right)^{S_{1}}}{\left(2^{S_{1}}-1\right)+S_{1}\left(T_{0}+1\right)^{S_{1}}}<\frac{\left(2^{S_{2}}-1\right)+S_{2}\left(\left(T_{0}+1\right)^{N_{0}}+1\right)^{S_{2}}}{\left(2^{S_{2}}-1\right)+S_{2}\left(T_{0}^{N_{0}}+1\right)^{S_{2}}}
$$

I will show this be construction. Clearly, if $\left(\frac{T_{0}+1}{T_{0}}\right)^{S_{1}}<\left(\frac{T_{0}+1}{T_{0}}\right)^{N_{0} S_{2}}$, then $\left(\frac{T_{0}+1}{T_{0}}\right)^{S_{1}}<$ $\left[\frac{\left(T_{0}+1\right)^{N_{0}}}{T_{0}^{N_{0}}}\right]^{S_{2}}$. It then implies that $\frac{S_{1}}{S_{1}}\left(\frac{\left(T_{0}+1\right)+1}{T_{0}+1}\right)^{S_{1}}<\frac{S_{2}}{S_{2}}\left[\frac{\left(T_{0}+1\right)^{N_{0}}+1}{T_{0}^{N_{0}}+1}\right]^{S_{2}}$ when all the parameters are greater than 1. Rewriting this inequality as $\frac{S_{1}\left(\left(T_{0}+1\right)+1 S^{S_{1}}\right.}{S_{1}\left(T_{0}+1\right)^{S_{1}}}<\frac{S_{2}\left(\left(T_{0}+1\right)^{N_{0}}+1\right)^{S_{2}}}{S_{2}\left(T_{0}^{N_{0}}+1\right)^{S_{2}}}$, it must then be true that

$$
\frac{\left(2^{S_{1}}-1\right)+S_{1}\left(T_{0}+1+1\right)^{S_{1}}}{\left(2^{S_{1}}-1\right)+S_{1}\left(T_{0}+1\right)^{S_{1}}}<\frac{\left(2^{S_{2}}-1\right)+S_{2}\left(\left(T_{0}+1\right)^{N_{0}}+1\right)^{S_{2}}}{\left(2^{S_{2}}-1\right)+S_{2}\left(T_{0}^{N_{0}}+1\right)^{S_{2}}}
$$

Therefore, the minimum ability needed in an organization increases faster at the upper level of the organization than at the bottom when the complexity of the task of the workers increases. And because one could presume that salaries are proportional to the required ability of the managers, it is not surprising then that the salary paid to top management personnel has grown much faster than the salary of the workers in the economy.

\subsection{Only one president}

The limited ability approach I develop in this paper also allows to explain why a corporation (or any organization for that matter) should have only one president that oversees all the firm's operations. 
In fact, not only do shareholders (or the other residual claimants) necessitate less computing power to oversee one president rather than many, the increase in the needed computing power when the complexity of the task increases is smaller.

CLAIM. It is efficient for an organization to have only one president because it minimizes the supervising cost of stakeholders.

Consider the computing ability needed to oversee the behavior of one president who sits at level $M$. Whatever the number of levels in the organization and the number of managers that the president supervises, the number of possible types the president can take is $T_{M}=T_{0}^{N_{0}}$, where $N_{0}$ is the number of workers in the organization and $T_{0}$ is their number of types. The minimum computing ability needed to supervise one president is $C\left(T_{M}, 1\right)=2\left(T_{0}^{N_{0}}\right)+\left(T_{0}^{N_{0}}\right)^{2}$. Clearly, this is a quadratic function in the number of types of the president.

If the organization decides to appoint two copresidents instead, then the number of possible types of each copresidents is $T_{0}^{\frac{N_{0}}{2}}$. The computing ability needed to over see the two copresidents that may be any of $T_{0}^{\frac{N_{0}}{2}}$ possible types is

$$
C\left(T_{0}^{\frac{N_{0}}{2}}, 2\right)=T_{0}^{\frac{N_{0}}{2} 2}\left[\left(2^{2}-1\right)+2\left(T_{0}^{\frac{N_{0}}{2}}+1\right)^{2}\right]
$$

We can distribute the terms so that we can rewrite this equality as

$$
C\left(T_{0}^{\frac{N_{0}}{2}}, 2\right)=5 T_{0}^{N_{0}}+2\left(T_{0}^{N_{0}}\right)^{2}+4\left(T_{0}^{N_{0}}\right)^{\frac{3}{2}}
$$

Clearly a more demanding task than with an unique president by an amount of

$$
C\left(T_{0}^{\frac{N_{0}}{2}}, 2\right)-C\left(T_{0}^{N_{0}}, 1\right)=3 T_{0}^{N_{0}}+\left(T_{0}^{N_{0}}\right)^{2}+4\left(T_{0}^{N_{0}}\right)^{\frac{3}{2}}
$$

Another interesting aspect of having an unique president is that the complexity function may be written as a simple quadratic function of his possible types. This means, amongst other things, that the change in the rate of increase of the contract's complexity is a constant, whatever the number of possible types he may take. Moreover, the rate of increase in the complexity of the contract as the number of types that the president may take is much smaller than in the case of multiple presidents. In the example used in this section, the (approximate) rate of increase in the complexity of the president's contract following an increase in the number of worker types is simply

$$
\frac{\partial C\left(T_{0}^{N_{0}}, 1\right)}{\partial T_{0}}=N_{0} T_{0}^{N_{0}-1}\left(2 T_{0}^{N_{0}}+2\right)
$$


When there are two presidents, the (approximate) rate of increase of the contract's complexity is given by

$$
\frac{\partial C\left(T_{0}^{\frac{N_{0}}{2}}, 2\right)}{\partial T_{0}}=N_{0} T_{0}^{N_{0}-1}\left[5+4 T_{0}^{N_{0}}+6\left(T_{0}^{N_{0}}\right)^{\frac{1}{2}}\right]>N_{0} T_{0}^{N_{0}-1}\left(2 T_{0}^{N_{0}}+2\right)
$$

The same can be said about the number of workers in the organization. The contract's complexity increases by a much slower rate when there is only one president at the helm. With one president, the (approximate) variation in the contract's complexity is given by

$$
\frac{\partial C\left(T_{0}^{N_{0}}, 1\right)}{\partial N_{0}}=\left(\ln T_{0}\right)\left[2\left(T_{0}^{N_{0}}\right)+2\left(T_{0}^{N_{0}}\right)^{2}\right]
$$

With two copresidents, the same derivative yields

$$
\frac{\partial C\left(T_{0}^{\frac{N_{0}}{2}}, 2\right)}{\partial N_{0}}=\left(\ln T_{0}\right)\left[5 T_{0}^{N_{0}}+4\left(T_{0}^{N_{0}}\right)^{2}+6\left(T_{0}^{N_{0}}\right)^{\frac{3}{2}}\right]
$$

What this means is that it is much easier for shareholders to adapt the president's compensation contract to changes in the environment when he is by himself. When more than one individual is at the helm of the organization, it is much more difficult to know where the ship is heading.

\subsection{Better technology}

Each manager's ability to keep track of many possible contingencies depends on three factors, two of which are the number of agents and the number of types. A third factor that I did not mention explicitly so far in the paper is how the managers are endowed with such or such computing ability, or how that ability may change with time or with the available technology. For instance, what impact did the information technology revolution of the late 20th century have on organizations?

CLAIM. If the level of information technology in the organization increases, then: 1the size of the organization will increase (more workers); 2- ratio of managers-to-workers will drop; and 3- the number of lower managers will decrease faster than the number of upper managers.

Assume people in the economy are initially endowed with different computing abilities $C^{i}(T, N ; \alpha)$, where $\alpha$ is some technology parameter such that $\frac{\partial C^{i}}{\partial \alpha}>0$ (i.e., better technology allows greater computing abilities). Say, for example, that $C^{i}(T, N ; \alpha)=\left[C^{i}(T, N)\right]^{1+\alpha}$ or that $C^{i}(T, N ; \alpha)=$ $(1+\alpha) C^{i}(T, N)$, with $\alpha \geq 0$. It would be interesting to see what impact an increase in the technology has on the size of the organization and on its structure. 
Suppose that the organization is initially composed of $N_{0}$ workers that can be any of $T_{0}$ types, and that the initial technology is such that $\alpha=\alpha_{0}=0$. Moreover, suppose the number of levels in the organization is $M$. The number of managers in the organization is then $\Sigma_{\mu=1}^{M-1} N_{\mu}$. At each level $\mu$ of the organization, managers need to have computing ability $C_{\mu}\left(T_{0}^{\Pi_{j=0}^{\mu-1} N_{j}}, \frac{N_{\mu-1}}{N_{\mu}}\right)$

To see why, note that an organization that has $N_{0}$ workers of $T_{0}$ possible types needs to hire $N_{1} C\left(T_{0}, S_{1} ; \alpha_{0}\right)$-ability level-1 managers to supervise these workers, with $S_{1}=\frac{N_{0}}{N_{1}}$. Since these $N_{1}$ managers may be any of $T_{0}^{S_{1}}$ possible types, $N_{2} C\left(T_{0}^{S_{1}}, S_{2} ; \alpha_{0}\right)$-ability level-2 managers are needed to supervise them, with $S_{2}=\frac{N_{1}}{N_{2}}$. These $N_{2}$ level-2 managers can then can any of $T_{0}^{S_{1} S_{2}}$ types. Therefore the $N_{3}$ level-3 managers must have ability $C\left(T_{0}^{S_{1} S_{2}}, S_{3} ; \alpha_{0}\right)$ to supervise the level-2 managers, with $S_{3}=\frac{N_{2}}{N_{3}}$. In general, the $N_{\mu}$ level-n managers must have ability $C\left(T_{0}^{N_{0} / N_{\mu-1}}, S_{\mu} ; \alpha_{0}\right)$ to supervise the $N_{\mu-1}$ level-( $\left.\mu-1\right)$ managers. Finally, given this setup, the company president who sits upon level $M$ needs to have ability $C\left(T_{0}^{N_{0} / N_{M-1}}, N_{M-1} ; \alpha_{0}\right)$ to supervise the top level managers who sit upon level $M-1$. As a result the number of managers in the organization is given by $\sum_{\mu=1}^{M-1} N_{\mu}$.

Suppose that a technological improvement increases the level-1 managers' ability to supervise workers without altering the number of types each worker may be. In other words, a change in $\alpha$ increases the computing ability of the managers without affecting $T_{0}$. What will happen to the organization's structure? Prior to the technological improvement the level-1 managers' ability was limited to $C\left(T_{0}, S_{1} ; \alpha_{0}\right)=C\left(T_{0}, \frac{N_{0}}{N_{1}} ; \alpha_{0}\right)$. Because the better technology increases implicitly the level-1 managers' ability, but does not alter the set of worker types, the only impact on the organization must come from a change in the number of workers each level-1 manager is able to supervise. In other words, an increase in $\alpha$ that does not change $T_{0}$ must result in an increase in $S_{1}$. Because $S_{1}$ is given by the ratio of the number of workers in the organization to the number of level-1 managers, each level-1 managers can increase the number of workers he supervises either through an increase in the number of workers in the organization $\left(N_{0}\right.$ increases), or though a reduction in the number of level-1 managers ( $N_{1}$ decreases).

Say the new number of workers that each level-1 manager is able to supervise when the new technology is put in place is $S_{1}^{\prime}$ (I shall note by $\bullet$ the numbers when the technology level is $\alpha_{1}$ ). Each level-1 manager's necessary computing ability is then $C\left(T_{0}, S_{1}^{\prime} ; \alpha_{1}\right)$, with $S_{1}^{\prime}=\frac{N_{0}^{\prime}}{N_{1}^{\prime}}$. The number of types that each level-1 manager can be is given by $T_{0}^{S_{1}^{\prime}}>T_{0}^{S_{1}}$. The number of level-2 managers $\left(N_{2}^{\prime}\right)$ will then be such that their minimum ability is $C\left(T_{0}^{S_{1}^{\prime}}, S_{2}^{\prime} ; \alpha_{1}\right)$, with $S_{2}^{\prime}=\frac{N_{1}^{\prime}}{N_{2}^{\prime}}$. In general, I then have that the number of level- $\mu$ managers $\left(N_{\mu}^{\prime}\right)$ will then be such that their minimum ability is $C\left(T_{0}^{N_{0}^{\prime} / N_{\mu-1}^{\prime}}, S_{\mu}^{\prime} ; \alpha_{1}\right)$, with $S_{\mu}^{\prime}=\frac{N_{\mu-1}^{\prime}}{N_{\mu}^{\prime}}$. 
In other words, when the number of level-1 managers does not change (i.e., $N_{1}=N_{1}^{\prime}$ ) even though the number of workers in the organization increases from $N_{0}$ to $N_{0}^{\prime}$, their ability must increase from $C\left(T_{0}, S_{1}\right)$ to $C\left(T_{0}, S_{1}^{\prime}\right)$, with $S_{1}=\frac{N_{0}}{N_{1}}$ and $S_{1}^{\prime}=\frac{N_{0}^{\prime}}{N_{1}}$. Will the number of level-2 managers increase? If the number of level-2 managers remains the same, what must the technology be so that the $N_{2}$ level-2 managers can supervise the $N_{1}$ level-1 managers that can take any of $T_{0}^{S_{1}^{\prime}}=T_{0}^{N_{0}^{\prime} / N_{1}}$ possible types? The level-2 managers' ability must then be at least equal to $C\left(T_{0}^{S_{1}^{\prime}}, S_{2}^{\prime} ; \alpha_{1}\right)$.

The growth in the ability of the level-1 managers can be measured by the ratio $\frac{C\left(T_{0}, S_{1}^{\prime}\right)}{C\left(T_{0}, S_{1}\right)}=$ $\frac{C\left(T_{0}, \frac{N_{0}^{\prime}}{N_{1}}\right)}{C\left(T_{0}, \frac{N_{0}}{N_{1}}\right)}$ if their number does not change. Assuming that the number of level-2 managers remains constant $\left(N_{2}^{\prime}=N_{2}\right)$, the growth in their ability can be measured by the ratio $\frac{C\left(T_{0}^{S_{1}^{\prime}}, S_{2}\right)}{C\left(T_{0}^{S_{1}}, S_{2}\right)}=$ $\frac{C\left(T_{0}^{N_{0}^{\prime} / N_{1}}, \frac{N_{1}}{N_{2}}\right)}{C\left(T_{0}^{N_{0} / N_{1}}, \frac{N_{1}}{N_{2}}\right)}$.

If $\frac{C\left(T_{0}, S_{1}^{\prime}\right)}{C\left(T_{0}, S_{1}\right)} \leq \frac{C\left(T_{0}^{S_{1}^{\prime}}, S_{2}\right)}{C\left(T_{0}^{S_{1}}, S_{2}\right)}$, then a technological increase that allows lower level managers to supervise more workers will necessitate the hiring of more upper level managers. Put differently, if $\frac{C\left(T_{0}, S_{1}^{\prime}\right)}{C\left(T_{0}, S_{1}\right)} \leq \frac{C\left(T_{0}^{S_{1}^{\prime}}, S_{2}\right)}{C\left(T_{0}^{S_{1}}, S_{2}\right)}$, then a technological increase that allows the number of upper managers to remain constant will allow the organization to layoff lower managers. For this to be the case, I need to show that $\frac{C\left(T_{0}, S_{1}^{\prime}\right)}{C\left(T_{0}, S_{1}\right)} \geq \frac{C\left(T_{0}^{S_{1}^{\prime}}, S_{2}\right)}{C\left(T_{0}^{S_{1}}, S_{2}\right)}$ is indeed true. This occurs when

$$
\frac{T_{0}^{S_{1}^{\prime}}\left[\left(2^{S_{1}^{\prime}}-1\right)+S_{1}^{\prime}\left(T_{0}+1\right)^{S_{1}^{\prime}}\right]}{T_{0}^{S_{1}}\left[\left(2^{S_{1}}-1\right)+S_{1}\left(T_{0}+1\right)^{S_{1}}\right]} \leq \frac{\left(T_{0}^{S_{1}^{\prime}}\right)^{S_{2}}\left[\left(2^{S_{2}}-1\right)+S_{2}\left(T_{0}^{S_{1}^{\prime}}+1\right)^{S_{2}}\right]}{\left(T_{0}^{S_{1}}\right)^{S_{2}}\left[\left(2^{S_{2}}-1\right)+S_{2}\left(T_{0}^{S_{1}}+1\right)^{S_{2}}\right]}
$$

Expanding the terms $S_{1}, S_{1}^{\prime}$ and $S_{2}$, the inequality becomes

$$
\frac{T_{0}^{\frac{N_{0}^{\prime}}{N_{1}}}\left[\left(2^{\frac{N_{0}^{\prime}}{N_{1}}}-1\right)+\frac{N_{0}^{\prime}}{N_{1}}\left(T_{0}+1\right)^{\frac{N_{0}^{\prime}}{N_{1}}}\right]}{T_{0}^{\frac{N_{0}}{N_{1}}}\left[\left(2^{\frac{N_{0}}{N_{1}}}-1\right)+\frac{N_{0}}{N_{1}}\left(T_{0}+1\right)^{\frac{N_{0}^{\prime}}{N_{1}}}\right)^{\frac{N_{1}}{N_{2}}}\left[\left(2^{\frac{N_{1}}{N_{2}}}-1\right)+\frac{N_{1}}{N_{2}}\left(T_{0}^{\frac{N_{0}^{\prime}}{N_{1}}}+1\right)^{\frac{N_{1}}{N_{2}}}\right]}
$$

With all variables integers, this inequality usually holds for $N_{0}^{\prime}>N_{0} \geq N_{1} \geq N_{2} \geq 1$ and $T>1$. There are circumstances where this inequality does not hold, two of which warrant some attention. 
In the first case, when $T_{0}=1$, the second term is always equal to 1 whereas the first term is always greater than 1 since $N_{0}^{\prime}>N_{0}$. This case is not very interesting since it concerns the case where agents can be only of 1 type, which does not make much economic sense. In the second case, when $N_{2}=N_{1}$, we have that the level-2 manager that oversees only one level-1 manager will benefit much more from a technological gain. This second case is more interesting as it tells us that a leap in information technology will allow the firm's residual claimant to supervise the organization's president at a lower cost (in terms of computing ability).

A leap in the information technology means that the structure of the organization will change. Even if the number of workers does not change, the number of managers in the organization will shrink so that the number of levels may be reduced. As a result, even if there is no tangible production gain to technology (i.e., the number of workers and the number of possible worker types remain the same), there is an efficiency gain at the information processing level so that the number of managers and the number of levels in the organization may be reduced.

\section{Conclusion}

The goal of this paper was to examine what happened to the design of a complete contract when agents must file a report based on information that is correlated. The traditional literature basically studies only two cases. In the first case, it is possible to extract all the information from the managers using arbitrarily large transfer schemes (see Crémer and McLean, 1988, and McAfee and Reny, 1992). In the second case, information is independent from one manager to the next so that it is impossible to design a contract that extracts all the information from the managers (see Townsend, 1979). In fact, the optimal contract is such that some rent must be paid to the manager who is best qualified. The case of correlated information with auditing and risk averse managers has not been addressed.

The complexity associated with designing contracts where information is correlated across managers is astonishing. In simple settings such as two managers having two possible types, a contract must specify at least 84 variables. When the number of managers and the number of types increase, the number of variables that need to be specified grows exponentially.

The implications of my results are two-fold. First, the complexity issue raised implies that fully specified contracts may be too expensive to implement in reality. This may explain why corporation resort to pay scales and subjective wording in their labor contracts. It may be less precise and it may allows some workers to shirk, but it is certainly easier and less costly to implement.

The second implication of my results is that it gives a rationale for hierarchies. When individuals have a limited ability to handle complex contracts in the sense that they can only keep track of a 
limited number of variables, it may be better for the organization to have a pyramidal structure since it increases the flow of information in the organization.

I do not pretend to offer a normative view of whether complete contracts within an organization are preferable to incomplete contracts. As such I do not claim that hierarchies create value. Indeed, hierarchies may still destroy value, as in McAfee and McMillan (1995) if the wages paid to middle management are higher than the losses incurred by the principal if contracts remained incomplete. Also, the gains associated with completing the contract may not outweigh the flexibility associated with incompleteness, as in Melumad et al. (1997). Nevertheless, the model I present offers a possible explanation as to the existence of hierarchies: They allow agents that have limited ability to gain access to all the information that is available to them 


\section{References}

1. Alchian, A. A. and H. Demsetz (1972). Production, Information Costs and Economic Organization. American Economic Review, 62: 777-795.

2. Anderlini, L. and L. Felli (1994). Incomplete Written Contracts: Undescribable States of Nature. Quarterly Journal of Economics, 109: 1085-1124.

3. Anderlini, L. and L. Felli (1999). Incomplete Contracts and Complexity Contracts. Theory and Decision, 46: 23-50.

4. Aoyagi, M. (1998). Correlated Types and Bayesian Incentive Compatible Mechanisms with Budget Balance. Journal of Economic Theory, 79: 142-151.

5. Baiman, S. and J. S. Demski (1980). Economically Optimal Performance Evaluation and Control Systems. Journal of Accounting Research, 18: 184-220.

6. Baniak, A. and A. Cukrowski (1999). Organizational Restructuring in Response to Changes in Information Processing Technology. Review of Economic Design, 4: 295-305.

7. Baron, D. P. and R. B. Myerson (1982). Regulating a Monopolist with Unknown Costs. Econometrica, 50: 911-930.

8. Bolton, P. and M. Dewatripont (1994). The Firm as a Communication Network. Quarterly Journal of Economics, 94: 809-840.

9. Bond, E. W. and K. J. Crocker (1997). Hardball and the Soft Touch: The Economics of Optimal Insurance Contracts with Costly State Verification and Endogenous Monitoring. Journal of Public Economics, 63: 239-254.

10. Boyer, M. M. (2003). Contracting under Ex post Moral Hazard, Costly Auditing and Principal Non-Commitment. Review of Economic Design, 8: 1-38.

11. Boyer, M. M. and P. González (2004). Optimal Audit Policies with Correlated Types. Economic Theory, 24: 325-334.

12. Brusco, S. (1998). Unique Implementation of the Full Surplus Extraction Outcome with Correlated Types. Journal of Economic Theory, 80: 185-200.

13. Cannings, K. (1988). The Earnings of Female and Male Middle Managers: A Canadian Case Study. The Journal of Human Ressources, 23: 34-56. 
14. Crémer, J. and R. P. McLean (1985). Optimal Selling Strategies Under Uncertainty for a Discriminating Monopolist when Demands are Interdependent. Econometrica, 53: 345-361.

15. Crémer, J. and R. P. McLean (1988). Full Extraction of the Surplus in Bayesian and Dominated Strategy Auctions. Econometrica, 56: 1247-1257.

16. Demougin, D. and D. A. Garvie (1991). Contractual Design with Correlated Information under Limited Liability. Rand Journal of Economics, 22: 477-489.

17. Dye, R.A. (1985). Costly Contract Contingencies. International Economic Review, 26: 233250.

18. Floyd, S. W. and B. Woolridge (1992). Middle Management Involvement in Strategy and Its Association with Strategic Type: A Research Note. Strategic Management Journal, 13: 153-167.

19. Gale, D. and M. Hellwig (1985). Incentive-Compatible Debt Contracts: The One-Period Problem. Review of Economic Studies, 52: 647-663.

20. Gale, D. and M. Hellwig (1989). Repudiation and Renegotiation: The Case of Sovereign Debt. International Economic Review, 30: 3-31.

21. Geanakoplos, J. and P. Milgrom (1991). A Theory of Hierarchies Based on Limited Managerial Attention. Journal of the Japanese and International Economies, 5: 205-225.

22. Guth, W. D. and I. C. MacMillan (1986). Strategy Implementation Versus Middle Management Self-Interest. Strategic Management Journal, 7: 313-327.

23. Hart, O. and B. Holmström (1987). The Theory of Contracts. In T.F. Bewley (ed.) Advances in Economic Theory, Fifth World Congress, Cambridge University Press.

24. Hart, O. and J. Moore (1988). Incomplete Contracts and Renegotiation. Econometrica, 56: $755-785$.

25. Jensen, M. C. and W. H. Meckling (1976). Theory of the Firm: Managerial Behavior, Agency Costs and Ownership Structure. Journal of Financial Economics, 3: 305-360.

26. Kaplan, R. S. (1975). The Significance and Investigation of Cost Variances: Survey and Extensions. Journal of Accounting Research, 13: 311-337.

27. Khalil, F. (1997). Auditing without Commitment. Rand Journal of Economics, 28: 629-640. 
28. Krasa, S. and A. Villamil (1994). Optimal Multi-Lateral Contracts. Economic Theory, 4: $167-187$.

29. Krasa, S., Villamil, A.: Optimal contracts when enforcement is a decision variable. Econometrica, 68: 119-134 (2000)

30. Lambert, R. A. (1985). Variance Investigation in Agency Settings. Journal of Accounting Research, 23: 633-647.

31. Lambert, R. A. (2001). Contracting Theory and Accounting. Journal of Accounting and Economics. 32: 3-87.

32. Lindbeck, A. and D. J. Snower (2000). Multitask Learning and the Reorganization of Work: From Toyloristic to Holistic Organization. Journal of Labor Economics, 18: 353-376.

33. Maskin, E. and J. Tirole (1999). Unforseen Contingencies and Incomplete Contracts. Review of Economic Studies, 66: 39-56.

34. McAfee, R. P.. and J. McMillan (1995). Organizational Diseconomic of Scale. Journal of Economics and Management Strategy, 4: 399-426.

35. McAfee, R. P. and P. J. Reny (1992). Correlated Information and Mechanism Design. Econometrica, 60:395-442.

36. Melumad, N., D. Mookhejee and S. Reichelstein (1997). Contract Complexity, Incentives and the Value of Delegation. Journal of Economic and Management Strategy, 6: 257-289.

37. Mookherjee, D. and I. Png (1989). Optimal Auditing, Insurance and Redistribution. Quarterly Journal of Economics, 104: 205-228.

38. Orbay, H. (2002). Information Processing Hierarchies. Journal of Economic Theory, 105: 370-407.

39. Picard, P. (1996). Auditing Claims in the Insurance Market with Fraud: The Credibility Issue. Journal of Public Economics, 63: 27-56.

40. Pinsonneault, A. and K. L. Kraemer (1997). Middle Management Downsizing: An Empirical Investigation of the Impact of Information Technology. Management Science, 43: 659-679.

41. Radner, R. (1986). The Internal Economy of Large Firms. The Economic Journal, Issue Supplement, 96: 1-22. 
42. Radner, R. (1992). Hierarchy: The Economics of Managing. Journal of Economic LIterature, 30: 1382-1415.

43. Radner, R. (1993). The Organization of Decentralized Information Processing. Econometrica, 61: 1109-1146.

44. Radner, R. and T. Van Zandt (1992). Information Processing in Firms and Returns to Scale. Annales d'économie et de statistique, 25/26: 265-298.

45. Rasmusen, E. B. (2001). Explaining Incomplete Contracts as the Result of Contract-Reading Costs. Advances in Economic Analysis 8 Policy, Vol. 1 no. 1, Article 2.

46. Robert, J. (1991). Continuity in Auction Design. Journal of Economic Theory, 55: 169-179.

47. Sappington, D. E. M. (1983). Limited Liability Contracts Between Principal and Agent. Journal of Economic Theory, 29: 1-21.

48. Segal, I. (1999). Complexity and Renegotiation: A Foundation for Incomplete Contracts. Review of Economic Studies, 66: 57-82.

49. Townsend, R. M. (1979). Optimal Contracts and Competitive Markets with Costly State Verification. Journal of Economic Theory, 21: 265-293.

50. White, R. E., J. N. Pearson and J. R. Wilson (1999). JIT Manufacturing: A Survey of Implementations in Small and Large U.S. Manufacturers. Management Science, 45: 1-15.

51. Williamson, O. (1967). Hierarchical Control and Optimum Firm Size. Journal of Political Economy, 75: 123-138.

52. Williamson, O. (1975). Market and Hierarchies. The Free Press, New York.

53. Williamson, O. (1985). The Economic Institutions of Capitalism. The Free Press, New York. 